\title{
DEGRADABILIDADE IN SITU DAS SILAGENS DE VARIEDADES DE CANA-DE-AÇÚCAR COM ADITIVOS
}

\section{IN SITU DEGRADABILITY OF SUGARCANE VARIETIES ENSILED WITH ADDITIVES}

\author{
Silva, G.W.V. ${ }^{1}$; Rocha Júnior, V.R. ${ }^{1 *}$; Rocha, W.J.B. ${ }^{1}$; Reis, S.T.1; Pires, D.A.A.; \\ Antunes, A.P.S.; Almeida Filho, S.H.C. ${ }^{1}$; Oliveira, L.M. ${ }^{1}$; Caldeira, L.A. ${ }^{1}$ e Souza, V.M. de ${ }^{1}$ \\ ${ }^{1}$ Universidade Estadual de Montes Claros. UNIMONTES. Bico da Pedra. Janaúba. Brasil. \\ *vicente.rocha@unimontes.br
}

\section{PalaVRas chaVe adicionais}

Degradabilidade efetiva. Degradabilidade potencial.

\section{RESUMO}

Objetivou-se com este trabalho avaliar a degradabilidade in situ da matéria seca, proteína bruta e fibra em detergente neutro das silagens de variedades de cana-de-açúcar com aditivos. A avaliação da degradabilidade foi realizada segundo um delineamento em blocos casualizados, em esquema fatorial $2 \times 6$ sendo duas variedades de cana (IAC 86-2480 e RB 86-7515), e cinco aditivos (ureia, $\mathrm{NaOH}, \mathrm{CaO}$, milho grão moído e Lactobacillus buchneri), mais a silagem-controle, com 3 blocos (animais). A fração solúvel e a degradabilidade efetiva da matéria seca das silagens com $\mathrm{NaOH}$ e CaO aumentaram. A fração solúvel e a degradabilidade efetiva da proteína bruta foram maiores nas silagens com ureia. A degradabilidade efetiva da fibra em detergente neutro das duas variedades foi maior nas silagens com $\mathrm{NaOH}$ e $\mathrm{CaO}$. As silagens com $\mathrm{NaOH}$ e $\mathrm{CaO}$ são de melhor valor nutricional, pois apresentam maior degradabilidade efetiva da matéria seca e fibra em detergente neutro. A variedade IAC 86-2480 apresenta melhor valor nutricional em relação à $R B$ 86-7515, devido à maior degradabilidade efetiva da matéria seca.

\section{SUMMARY}

The aim of this work was to evaluate the in situ degradability of the dry matter, crude protein and neutral detergent fiber of two sugarcane varieties ensiled with additives. The evaluation of the degradability was carried out according to a random blocks design, in factorial scheme $2 \times 6$, being two

\author{
AdDitiOnAL KEYWORDS \\ Effective degradability. Potential degradabilbity.
}

cane varieties (IAC 86-2480 and RB 86-7515), and five additives (urea, $\mathrm{NaOH}, \mathrm{CaO}$, corn and Lactobacillus buchneri), plus the control silage, with 3 blocks (animals). The $\mathrm{NaOH}$ and the $\mathrm{CaO}$ increased the values of soluble fraction and the effective degradability of dry matter. The soluble fraction and the effective degradability of the crude protein were higher with urea. The effective degradability of the neutral detergent fiber of the two varieties was higher in the silages with $\mathrm{NaOH}$ and $\mathrm{CaO}$. The silages treated with $\mathrm{NaOH}$ and $\mathrm{CaO}$ are the best in nutritional value, because of the highest effective degradability of dry matter and neutral detergent fiber. The IAC 86-2480 variety presents better nutritional value than RB 86-7515, due to the highest effective degradability of dry matter.

\section{INTRODUÇÃO}

Pesquisas têm permitido a obtenção de aditivos para inibir a fermentação alcoólica da cana ensilada realizada por leveduras epifíticas, característica desse material. Porém, a maioria destaca apenas a composição bromatológica das silagens, as perdas durante o processo de conservação e desempenho de animais. Sendo incipientes os dados sobre a degradabilidade de nutrientes das silagens (Schmidt et al., 2007).

Quando a fibra é de boa qualidade, o 
alimento digerido pode ser substituído por mais alimento consumido, potencializando a produtividade animal, mas se a degradabilidade for prolongada, a repleção ruminal limitará o consumo. A cana apresenta uma fibra de baixa degradabilidade, sendo importante selecionar variedades com degradabilidade mais elevada (Freitas et al., 2006).

Objetivou-se avaliar a degradabilidade in situ das silagens de duas variedades de cana-de-açúcar com diferentes aditivos.

\section{MATERIAL E MÉTODOS}

O experimento foi realizado no Departamento de Ciências Agrárias da Universidade Estadual de Montes Claros (UNIMONTES), Campus de Janaúba - MG, Brasil.

Utilizaram-se duas variedades de cana (IAC 86-2480 e RB 86-7515) provenientes da fazenda experimental da UNIMONTES. A cana foi picada utilizando ensiladeira mecânica estacionária, em partículas com tamanho médio inferior a $2 \mathrm{~cm}$. A variedade IAC 86-2480 é um híbrido interespecífico resultante de cruzamento, envolvendo o parental US 71-399 e uma variedade desconhecida, selecionado em campo de seedings instalado em Ribeirão Preto/SP (Marques e Silva, 2008). A variedade RB 86-7515 foi lançada pela Universidade Federal de Viçosa, e resultou do cruzamento da variedade RB 72454 com outra variedade indefinida.

No ensaio de degradabilidade in situ, foi utilizado um delineamento em blocos casualizados com esquema fatorial $2 \times 6$, sendo duas variedades de cana (IAC 862480 e RB 86-7515), cinco aditivos (ureia, $\mathrm{NaOH}, \mathrm{CaO}$, milho grão moído e Lactobacillus buchneri), mais a silagem-controle, com 3 blocos (animais). O ensaio teve duração de 14 dias, sendo 10 dias de adaptação à dieta e 4 dias de incubação.

As doses dos aditivos para cada tratamento em relação à matéria verde foram de: $1 \%$ de ureia, $1,5 \%$ de $\mathrm{NaOH}, 2 \%$ de $\mathrm{CaO}$, $5 \%$ de milho grão moído e a cepa NCIMB
40 788, do inoculante comercial Silo Max ${ }^{\circledR}$, na dose de 2,5 x 1010 UFC/g de forragem.

Foram utilizados silos experimentais cilíndricos, de PVC, de pesos conhecidos, com $40 \mathrm{~cm}$ de comprimento e $10 \mathrm{~cm}$ de diâmetro. A forragem foi homogeneizada aos aditivos, depositada nos silos e compactada com êmbolo de madeira. Os silos foram fechados com tampas de PVC dotadas de válvula tipo Bunsen e mantidos à temperatura ambiente por 60 dias. Após este período, cada silo foi aberto e a silagem foi homogeneizada e pré-secada em estufa de ventilação forcada a $55^{\circ} \mathrm{C}$ até peso constante. As amostras a serem incubadas foram então moídas em peneiras com crivo de 2 mm. Foram utilizados sacos de náilon medindo 10 x $20 \mathrm{~cm}$, com porosidade aproximada de $50 \mathrm{~mm}$, fechados a quente em máquina seladora.

Foram colocados 24 sacos (2 variedades $\mathrm{x} 6$ tratamentos, sendo 5 aditivos mais a silagem controle, em duplicata) por tempo de incubação (0, 6, 12, 24, 48, 72 e 96 horas), em cada animal. Todos os sacos, antes e após o período de incubação, foram colocados em estufas a $55{ }^{\circ} \mathrm{C}$ com ventilação forçada por 48 horas, retirados e colocados em dessecador até resfriarem, sendo então pesados.

As amostras das silagens foram pesadas e colocadas nos sacos de náilon, em quantidades de MS suficientes para manter a relação proposta por Nocek (1988), em torno de $20 \mathrm{mg}$ de $\mathrm{MS} / \mathrm{cm}^{2}$ de área superficial do saco. Em seguida, os sacos de náilon foram fechados e colocados em estufa com ventilação forçada a uma temperatura de $55^{\circ} \mathrm{C}$ durante 24 horas, e então depositados em dessecador antes de serem novamente pesados.

Os sacos de náilon foram colocados em sacolas de filó, medindo 15 x 30 cm, juntamente com pesos de chumbo de $100 \mathrm{~g}$. As sacolas foram amarradas com um fio de náilon, deixando um comprimento livre de 1 m para que as mesmas tivessem livre movimentação nas fases sólidas e líquidas 
do rúmen. As sacolas foram então depositadas na região do saco ventral do rúmen por $0,6,12,24,48,72$ e 96 horas, sendo a incubação dos sacos feita na ordem inversa dos tempos, para serem retirados todos ao mesmo tempo, ao final do período, e desta forma, promover lavagem uniforme do material por ocasião da retirada do rúmen.

Após o término do período de incubação, as sacolas de filó foram retiradas do rúmen, abertas, e os sacos de náilon, contendo as amostras, foram imediatamente lavados manualmente em água corrente até que esta se apresentasse limpa, sendo em seguida colocados em estufas a $55{ }^{\circ} \mathrm{C}$ durante 72 horas, resfriado em dessecador e pesados. Os sacos referentes ao tempo zero, para determinar a fração solúvel, foram introduzidos na massa ruminal e imediatamente retirados, recebendo, o mesmo tratamento destinado aos demais tempos. Obtida a matéria seca das amostras, as mesmas foram utilizadas para estimação da proteína bruta e fibra em detergente neutro, segundo metodologia descrita em Silva e Queiroz (2002). Amostras das duas variedades de cana-de-açúcar foram analisadas para os teores de matéria seca, proteína bruta, extrato etéreo, matéria mineral, fibra em detergente neutro, fibra em detergente ácido, celulose, hemicelulose e lignina, de acordo com metodologia descrita por Silva e Queiroz (2002) e os carboidratos não fibrosos forma calculados segundo Sniffen et al. (1992). A composição química das duas variedades estudadas encontra-se na tabela I.

Os dados obtidos foram ajustados para uma equação de regressão não linear pelo método de Gauss-Newton (Neter et al., 1985), através do software SAS (SAS Institute, 2000), conforme a equação proposta por Orskov e McDonald (1979):

$$
\mathrm{Y}=\mathrm{a}+\mathrm{b}\left(1-\mathrm{e}^{-c t}\right)
$$

em que:

$\mathrm{Y}=$ degradabilidade acumulada do componente nutritivo analisado, após um tempo t; $a=$ intervalo da curva de degradabilidade quando $\mathrm{t}=0$, correspondendo à fração solúvel do componente nutritivo analisado;

$b=$ potencial de degradabilidade da fração insolúvel do componente nutritivo analisado;

$a+b=$ degradabilidade potencial do componente nutritivo analisado, quando o tempo t não é um fator limitante;

$\mathrm{c}=$ taxa de degradação por ação fermentativa da fração b.

Uma vez calculadas as constantes a, b e c estas foram aplicadas à equação proposta por Orskov e McDonald (1979):

$$
P=\frac{a+b \cdot c}{c+k}
$$

Emque:

$\mathrm{P}=$ degradabilidade ruminal efetiva do componente nutritivo analisado;

$k=$ taxa de passagem ruminal do alimento $(0,05 / h)$.

As degradabilidades efetivas ruminais foram calculadas e expressas em termos de matéria seca, proteína bruta e fibra em detergente neutro efetivamente degradadas no rúmen, para uma taxa de passagem de $5 \% / h$.

As variáveis foram analisadas usando o procedimento GLM do programa estatístico SAS (SAS Institute, 2000), depois de obtidos os valores dos parâmetros fração solúvel (A), fração insolúvel potencialmente degradável (B), taxa de degradação (c), fração indegradável (FI), degradabilidade potencial (DP) e degradabilidade efetiva (DE), os mesmos foram submetidos à análise de variância por meio do programa SISVAR (Ferreira, 2000), e quando o teste F apresentou significância para os fatores principais e suas interações as médias dos tratamentos foram submetidas ao teste de Scott-Knott a $5 \%$ de probabilidade.

\section{RESULTADOSEDISCUSSÃO}

Para a fração solúvel da MS, a variedade RB 86-7515 apresentou os maiores valores nas silagens com $\mathrm{NaOH}$ e $\mathrm{CaO}$, enquanto a 
Tabela I. Composição bromatológica de duas variedades de cana-de-açúcar in natura. (Bromatological composition of two varieties of sugarcane in natura).

IAC 86-2480 RB 86-7515

\begin{tabular}{lcc}
\hline Matéria seca & 26,12 & 28,62 \\
Proteína bruta & 1,26 & 3,60 \\
Fibra detergente neutro & 36,79 & 41,32 \\
Fibra detergente ácido & 21,59 & 23,69 \\
Hemicelulose & 17,63 & 15,19 \\
Celulose & 17,22 & 17,93 \\
Lignina & 6,98 & 6,85 \\
Extrato etéreo & 1,88 & 2,01 \\
Cinzas & 3,81 & 3,22 \\
Carboidratos n. fibrosos & 51,73 & 54,38 \\
\hline
\end{tabular}

IAC 86-2480 apresentou maiores teores nos outros tratamentos. Os maiores teores de fração A nas silagens com NAOH e $\mathrm{CaO}$ podem ser explicados pelo fato das substâncias alcalinizantes terem a capacidade de solubilizar parte da fração fibrosa. Os álcalis atuam no complexo ligninacarboidratos alterando a estrutura dos polissacarídeos, expandindo a celulose, rompendo ligações intermoleculares e solubilizando parte da hemicelulose (Amaral et al., 2009).

Os teores da fração insolúvel potencialmente degradável (B) da MS, diferiram de acordo com os aditivos utilizados $(\mathrm{p}<0,05)$ apenas na variedade RB 86-7515. As silagens com ureia, L. buchneri e a controle apresentaram os maiores valores de fração $\mathrm{B}$, provavelmente por terem apresentado menores valores de fração $A$, já que na RB 86-7515 esses mesmos aditivos apresentaram menores valores de fração A quando comparados à IAC 86-2480. Já as silagens com os álcalis revelaram menores valores de fração B, por terem solubilizado parte da fração fibrosa, o que é confirmado pelos elevados valores de fração solúvel. As silagens com milho apresentaram menores valores de fração $B$, pela contribuição do milho com sua parte solúvel, incrementando, assim, os valores da fração A.

Quanto à taxa de degradação ruminal da MS, os aditivos diferiram entre si apenas na variedade IAC 86-2480, cujas silagens tratadas com $\mathrm{NaOH}, \mathrm{CaO}$ e milho apresentaram valores superiores em relação aos demais e a silagem controle. Entre variedades, o único aditivo que apresentou diferença foi o $\mathrm{CaO}$, com a IAC 86-2480 apresentando maior valor (3,9\%) em relação à RB 86-7515 (1,9\%). As silagens com $\mathrm{NaOH}$ e $\mathrm{CaO}$ na variedade IAC 86-2480 podem ter apresentado maiores valores de c, por terem apresentado maior fração solúvel da MS, e o milho por ter melhorado o valor nutricional da silagem, exigindo, assim, menor tempo de retenção no rúmen para ser degradada.

A ureia também melhorou o valor nutricional das silagens, pelo incremento no teor de $\mathrm{PB}$, o que pode favorecer o crescimento microbiano, melhorar o aproveitamento da fibra e aumentar a digestibilidade da forragem, no entanto, não houve melhora na qualidade da fibra com a adição de ureia, embora Reis et al. (1990) afirmarem que a ureia, ao ser adicionada na forragem durante o processo de ensilagem, é convertida em amônia, que é capaz de romper algumas ligações ésteres da fração fibrosa, podendo maximizar a digestibilidade da silagem. Na variedade RB 86-7515 era de se esperar que os mesmos aditivos também demonstrassem maiores valores de c, já que apresentaram maiores frações solúveis, porém tal fato não ocorreu, sendo todos os aditivos dentro desta variedade semelhantes entre si. Possivelmente, pelo fato da fibra da variedade RB 86-7515 ser de qualidade inferior, em relação à IAC 86-2480, conforme pode ser verificado na tabela I.

Para fração indegradável, os aditivos diferiram apenas na variedade RB 86-7515, sendo que as silagens com ureia, milho grão moído, L. buchneri e a silagem controle revelaram maiores valores e foram semelhantes entre si. As variedades diferiram apenas no tratamento com milho grão moído, 
em que a RB 86-7515 apresentou maior valor de fração indegradável (40,77\%), em relação a IAC 86-2480 (31,04\%).

Na RB 86-7515 a silagem com $\mathrm{NaOH}$ demonstrou a maior degradabilidade potencial $(85,43 \%)$, seguida pela silagem com $\mathrm{CaO}(73,40 \%)$. Os outros aditivos apresentaram menores valores, não diferindo entre si. Entre variedades, houve diferenças apenas entre as silagens com milho grão moído, em que a variedade IAC 86-2480 exibiu o maior valor (68,96 \%) em relação a RB 867515 (59,23 \%). Essa diferença pode ser justificada devido à variedade RB 86-7515 ter apresentado maior valor para a fração indegradável (40,77 \%) em comparação à IAC 86-2480 (31,04\%) nesse tratamento.

Na variedade IAC 86-2480, o maior valor de degradabilidade efetiva da MS foi en- contrado na silagem com $\mathrm{NaOH}(65,13 \%)$, seguida pela silagem com $\mathrm{CaO}(57,21 \%)$, a silagem com L. buchneri (44,13\%) e a controle $(44,54 \%)$ apresentaram os menores valores, sendo semelhantes. Na variedade RB 86-7515, a silagem com $\mathrm{NaOH}$ também apresentou maior valor (67,38\%), com a silagem com L. buchneri (34,72\%) e a controle (32,29 \%) apresentando os menores valores e não diferindo entre si. A diferença entre variedades foi constatada em todos os tratamentos, exceto nas silagens que receberam $\mathrm{CaO}$. A variedade RB 86-7515 exibiu maiores valores, apenas nas silagens com $\mathrm{NaOH}$, enquanto a IAC 86-2480 apresentou maior DE da MS nos outros tratamentos. Isso pode ser justificado pela melhor qualidade da fibra da variedade IAC 86-2480.

Tabela II. Parâmetros da degradação (\%) ruminal da matéria seca das silagens de duas variedades de cana-de-açúcar com diferentes aditivos. (Parameters of the rumen degradation (\%) of the dry matter of two sugarcane varieties ensiled with different additives).

\begin{tabular}{|c|c|c|c|c|c|c|}
\hline $\begin{array}{c}\text { Variedades } \\
\text { Aditivos }\end{array}$ & A & B & c & $\mathrm{FI}$ & DP & DE \\
\hline \multicolumn{7}{|l|}{ AC86-2480 } \\
\hline Ureia & $41,97^{A C}$ & $32,25^{\mathrm{Aa}}$ & $1,7^{\mathrm{Ab}}$ & $25,78^{\mathrm{Aa}}$ & $74,22^{\mathrm{Aa}}$ & $49,98^{A C}$ \\
\hline $\mathrm{NaOH}$ & $55,96^{\mathrm{Ba}}$ & $25,26^{\mathrm{Aa}}$ & $2,9^{\mathrm{Aa}}$ & $18,78^{\mathrm{Aa}}$ & $81,22^{\mathrm{Aa}}$ & $65,13^{\mathrm{Ba}}$ \\
\hline $\mathrm{CaO}$ & $45,97^{\mathrm{Bb}}$ & $26,75^{\mathrm{Aa}}$ & $3,9^{\mathrm{Aa}}$ & $27,28^{\mathrm{Aa}}$ & $72,72^{\mathrm{Aa}}$ & $57,21^{\mathrm{Ab}}$ \\
\hline Milho & $36,32^{\mathrm{Ad}}$ & $32,65^{\mathrm{Aa}}$ & $3,5^{\mathrm{Aa}}$ & $31,04^{\mathrm{Ba}}$ & $68,96^{\mathrm{Aa}}$ & $49,64^{A \mathrm{C}}$ \\
\hline L. buchneri & $34,15^{\mathrm{Ad}}$ & $33,27^{\mathrm{Aa}}$ & $2,1^{\mathrm{Ab}}$ & $32,57^{\mathrm{Aa}}$ & $67,43^{\mathrm{Aa}}$ & $44,13^{\text {Ad }}$ \\
\hline Controle & $35,36^{\mathrm{Ad}}$ & $32,71^{\mathrm{Aa}}$ & $1,9^{A b}$ & $31,93^{\mathrm{Aa}}$ & $68,07^{\mathrm{Aa}}$ & $44,54^{\mathrm{Ad}}$ \\
\hline \multicolumn{7}{|l|}{ RB86-7515 } \\
\hline Ureia & $26,98^{\mathrm{Bd}}$ & $35,90^{\mathrm{Aa}}$ & $2,2^{\mathrm{Aa}}$ & $37,12^{\mathrm{Aa}}$ & $62,88^{A C}$ & $37,98^{\mathrm{Bd}}$ \\
\hline $\mathrm{NaOH}$ & $60,15^{\mathrm{Aa}}$ & $25,28^{\mathrm{Ab}}$ & $2,1^{\mathrm{Aa}}$ & $14,57^{\mathrm{Ac}}$ & $85,43^{\mathrm{Aa}}$ & $67,38^{\mathrm{Aa}}$ \\
\hline $\mathrm{CaO}$ & $50,11^{A b}$ & $23,29^{A b}$ & $1,9^{\mathrm{Ba}}$ & $26,59^{A b}$ & $73,40^{\mathrm{Ab}}$ & $56,12^{\mathrm{Ab}}$ \\
\hline Milho & $33,95^{B C}$ & $25,27^{\mathrm{Ab}}$ & $3,1^{\mathrm{Aa}}$ & $40,77^{\mathrm{Aa}}$ & $59,23^{\mathrm{BC}}$ & $43,71^{\mathrm{BC}}$ \\
\hline L. buchneri & $24,46^{\mathrm{Be}}$ & $38,51^{\mathrm{Aa}}$ & $2,0^{\mathrm{Aa}}$ & $37,03^{\mathrm{Aa}}$ & $62,97^{A C}$ & $34,72^{\mathrm{Be}}$ \\
\hline Controle & $22,24^{\mathrm{Be}}$ & $41,81^{\mathrm{Aa}}$ & $1,7^{\mathrm{Aa}}$ & $35,96^{\mathrm{Aa}}$ & $64,04^{A C}$ & $32,29^{\mathrm{Be}}$ \\
\hline CV (\%) & 3,09 & 16,47 & 27,57 & 18,75 & 7,96 & 2,38 \\
\hline
\end{tabular}

Archivos de zootecnia vol. 63, núm. 241, p. 175. 
Os maiores valores da degradabilidade efetiva, nas silagens com NAOH e CaO, são justificados pela ação dos álcalis em solubilizar parte da fração fibrosa, fato confirmado pelos maiores valores da fração solúvel nestes tratamentos. Cavali et al. (2006), analisando diferentes doses de $\mathrm{CaO}$ em silagens de cana-de-açúcar, observaram maiores coeficientes de digestibilidade nas silagens tratadas. As silagens tratadas com ureia e milho grão moído demonstraram valores de degradabilidade efetiva intermediários, o que ocorreu, provavelmente, devido à participação da parte degradável destes aditivos, já que a ureia é $100 \%$ degradável e o milho chega a apresentar degradabilidade efetiva de 41,28 a 62,27 \% (Passini et al., 2004).

Com relação à porcentagem de desaparecimento da MS, verificou-se predomi- nância para, seguidas das silagens com $\mathrm{CaO}$. $\mathrm{O}$ maior desaparecimento ruminal da MS das silagens aditivadas com $\mathrm{NaOH}$ e $\mathrm{CaO}$ no tempo zero ocorreu devido à maior presença de compostos solúveis em relação às demais silagens, o que é proporcionado pelo efeito hidrolítico desses álcalis, na solubilização da fração fibrosa dos alimentos.

No último período de incubação (96 horas), as silagens das duas variedades com $\mathrm{NaOH}$ apresentaram os maiores valores de desaparecimento da MS, seguidas pelas silagens tratadas com $\mathrm{CaO}$. Os menores valores foram apresentados pelas silagens da variedade RB 86-7515 com L. buchneri e silagem controle, confirmando o que ocorreu no tempo zero. A diferença no desaparecimento final (96 horas) da MS pode ter sido influenciada pela qualidade da fibra, já que a variedade IAC 86-2480 apresenta.

Tabela III. Desaparecimento da matéria seca (\%) das silagens de duas variedades de canade-açúcar com diferentes aditivos. (Disappearance of the dry matter (\%) of two varieties of sugarcane ensiled with different additives).

\begin{tabular}{lcccccccc}
\hline \multirow{2}{*}{$\begin{array}{l}\text { Variedad } \\
\quad \text { Aditivos }\end{array}$} & 0 & 6 & 12 & 24 & 48 & 72 & 96 & $\mathrm{R}^{2}$ \\
\hline IAC 86-2480 & & & & & & & & \\
$\quad$ Ureia $^{1}$ & 41,97 & 46,08 & 48,90 & 53,74 & 60,91 & 65,69 & 71,87 & 0,97 \\
NaOH $^{2}$ & 55,96 & 59,97 & 63,35 & 68,57 & 74,89 & 78,05 & 79,63 & 0,96 \\
CaO $^{3}$ & 45,97 & 51,56 & 55,98 & 62,24 & 68,62 & 70,11 & 71,09 & 0,97 \\
Milho $^{4}$ & 36,32 & 42,54 & 47,58 & 54,96 & 62,96 & 66,39 & 67,86 & 0,99 \\
L. buchneri $^{5}$ & 34,15 & 39,17 & 42,70 & 48,53 & 55,53 & 60,31 & 63,17 & 0,98 \\
Controle $^{6}$ & 35,36 & 38,98 & 42,19 & 47,59 & 55,24 & 60,04 & 62,04 & 0,95 \\
& & & & & & & & \\
RB 86-7515 & & & & & & & & \\
$\quad$ Ureia $^{7}$ & 26,98 & 31,44 & 35,34 & 41,76 & 50,45 & 55,57 & 58,58 & 0,95 \\
NaOH $^{8}$ & 60,15 & 63,08 & 65,67 & 69,99 & 76,00 & 79,67 & 80,91 & 0,96 \\
CaO $^{9}$ & 50,11 & 52,65 & 54,91 & 58,72 & 64,15 & 67,57 & 69,73 & 0,95 \\
Milho $^{10}$ & 33,95 & 38,32 & 41,93 & 47,38 & 53,68 & 56,63 & 58,01 & 0,97 \\
L. buchneri $^{11}$ & 24,46 & 28,83 & 32,70 & 39,18 & 48,27 & 53,89 & 57,36 & 0,94 \\
Controle $^{12}$ & 22,24 & 26,28 & 29,93 & 36,21 & 45,51 & 51,71 & 55,83 & 0,98 \\
\hline
\end{tabular}

$\mathrm{R}^{2}=$ coeficiente de determinação; ${ }^{1} \mathrm{Y}=41,97+32,25\left(1-\mathrm{e}^{-0,017^{*}}\right) ;{ }^{2} \mathrm{Y}=55,96+25,26\left(1-\mathrm{e}^{-0,029^{*}}\right) ;{ }^{3} \mathrm{Y}=$ $45,97+26,75\left(1-\mathrm{e}^{-0,039^{*}}\right) ;{ }^{4} \mathrm{Y}=36,32+32,65\left(1-\mathrm{e}^{-0,035^{*}}\right) ;{ }^{5} \mathrm{Y}=34,15+33,27\left(1-\mathrm{e}^{-0,021^{*}}\right) ;{ }^{6} \mathrm{Y}=35,36+32,71$ $\left(1-\mathrm{e}^{-0,019^{*}}\right) ;{ }^{7} \mathrm{Y}=26,98+35,90\left(1-\mathrm{e}^{-0,022^{*}}\right) ;{ }^{8} \mathrm{Y}=60,15+25,28\left(1-\mathrm{e}^{-0,021^{*}}\right) ;{ }^{9} \mathrm{Y}=50,11+23,29\left(1-\mathrm{e}^{-0,019^{*}}\right)$; ${ }^{10} \mathrm{Y}=33,95+25,27\left(1-\mathrm{e}^{-0,031^{*}}\right) ;{ }^{11} \mathrm{Y}=24,46+38,51\left(1-\mathrm{e}^{-0,02^{4} \mathrm{t}}\right) ;{ }^{12} \mathrm{Y}=22,24+41,81\left(1-\mathrm{e}^{-0,017^{*}}\right)$.

Archivos de zootecnia vol. 63, núm. 241, p. 176. 
$\mathrm{Na}$ variedade IAC 86-2480, o maior valor de fração solúvel da PB $(\mathrm{p}>0,05)$ foi encontrado na silagem com ureia $(83,09 \%)$, com a silagem controle apresentando o menor valor (10,51 \%). Na RB 86-7515, a silagem com ureia apresentou maior teor de fração solúvel $(77,30 \%)$, seguida pela silagem com $\mathrm{NaOH}(36,69 \%)$, com a silagem controle apresentando o menor valor (10,92\%). A diferença entre variedades foi constatada nas silagens com ureia, $\mathrm{NaOH}$, $\mathrm{CaO}$ e L. buchneri. A variedade IAC 86-2480 demonstrou maior teor de fração solúvel nas silagens com ureia, $\mathrm{CaO}$ e L. buchneri, enquanto a RB 86-7515 teve maior valor na silagem com $\mathrm{NaOH}(36,69 \%)$ (tabela IV).

As silagens com ureia revelaram maiores valores de fração solúvel da $\mathrm{PB}$, pelo fato dessa ser uma fonte de nitrogênio não protéico (NNP) 100 \% solúvel. Na variedade $\mathrm{RB}$ 86-7515, a silagem com $\mathrm{NaOH}$ apresentou valor intermediário de fração solúvel da PB (36,69\%), possivelmente pelo fato desse álcali ter solubilizado parte da PB da silagem (Lucci, 1997).

Para fração insolúvel potencialmente degradável da PB, na variedade IAC 862480, a silagem com ureia exibiu menor valor $(10,77 \%)$, com a silagem controle apresentando o maior teor (64,68\%). Também na RB 86-7515, a silagem com ureia demonstrou menor teor de B (12,80\%), e a silagem controle evidenciou o maior valor (65,70\%). A diferença entre variedades foi detectada nas silagens com $\mathrm{NaOH}, \mathrm{CaO}$, milho grão moído e L . buchneri, em que a RB 86-7515 apresentou valores inferiores nas silagens com $\mathrm{NaOH}$, milho grão moído e

Tabela IV. Parâmetros da degradação ruminal da proteína bruta das silagens de duas variedades de cana-de-açúcar com diferentes aditivos. (Parameters of the rumen degradation of the crude protein of two sugarcane varieties ensiled with different additives).

\begin{tabular}{|c|c|c|c|c|c|c|}
\hline \multicolumn{7}{|l|}{ Variedades } \\
\hline Aditivos & A & B & c & $\mathrm{FI}$ & DP & DE \\
\hline \multicolumn{7}{|l|}{ IAC86-2480 } \\
\hline Ureia & $83,09^{\mathrm{Aa}}$ & $10,77^{\mathrm{Ad}}$ & $3,63^{\mathrm{Aa}}$ & $6,12^{\mathrm{Bb}}$ & $93,87^{\text {Аа }}$ & $86,02^{\mathrm{Aa}}$ \\
\hline $\mathrm{NaOH}$ & $18,64^{\mathrm{BC}}$ & $59,67^{\mathrm{Ab}}$ & $2,00^{\mathrm{BC}}$ & $21,67^{\mathrm{Aa}}$ & $78,32^{\mathrm{Ab}}$ & $35,17^{\mathrm{Bd}}$ \\
\hline $\mathrm{CaO}$ & $20,38^{A b}$ & $55,05^{\mathrm{Bc}}$ & $2,23^{\mathrm{AC}}$ & $24,56^{\mathrm{Aa}}$ & $75,43^{\mathrm{Ab}}$ & $37,12^{\mathrm{Ad}}$ \\
\hline Milho & $21,92^{\mathrm{Ab}}$ & $53,96^{A C}$ & $3,9^{\mathrm{Aa}}$ & $24,11^{\mathrm{Ba}}$ & $75,88^{\mathrm{Ab}}$ & $45,55^{\mathrm{Ab}}$ \\
\hline L. buchneri & $20,85^{A b}$ & $55,94^{\mathrm{AC}}$ & $2,93^{A b}$ & $23,21^{\mathrm{Ba}}$ & $76,79^{\mathrm{Ab}}$ & $41,11^{\mathrm{AC}}$ \\
\hline Controle & $10,51^{\mathrm{Ad}}$ & $64,68^{\mathrm{Aa}}$ & $2,6^{\mathrm{AC}}$ & $24,80^{\mathrm{Aa}}$ & $71,69^{\mathrm{Ab}}$ & $32,42^{\mathrm{Ae}}$ \\
\hline \multicolumn{7}{|l|}{ RB86-7515 } \\
\hline Ureia & $77,30^{\mathrm{Ba}}$ & $12,80^{\mathrm{Af}}$ & $3,5^{\mathrm{Aa}}$ & $9,89^{\mathrm{Ae}}$ & $90,10^{\mathrm{Aa}}$ & $82,55^{\mathrm{Ba}}$ \\
\hline $\mathrm{NaOH}$ & $36,69^{A b}$ & $42,71^{\mathrm{Be}}$ & $2,93^{A b}$ & $20,58^{\mathrm{Ad}}$ & $79,41^{\mathrm{Ab}}$ & $52,41^{\mathrm{Ab}}$ \\
\hline $\mathrm{CaO}$ & $16,50^{\mathrm{Bd}}$ & $58,56^{\mathrm{Ab}}$ & $2,36^{A C}$ & $24,92^{\mathrm{AC}}$ & $75,07^{A b}$ & $35,37^{\text {Ad }}$ \\
\hline Milho & $20,54^{A C}$ & $45,33^{B d}$ & $3,7^{\mathrm{Aa}}$ & $34,12^{\mathrm{Aa}}$ & $65,87^{\mathrm{BC}}$ & $39,73^{B C}$ \\
\hline L. buchneri & $18,09^{\mathrm{Bd}}$ & $52,95^{\mathrm{BC}}$ & $2,00^{\mathrm{BC}}$ & $28,95^{\mathrm{Ab}}$ & $61,04^{\mathrm{BC}}$ & $32,95^{\mathrm{Bd}}$ \\
\hline Controle & $10,92^{\mathrm{Ae}}$ & $65,70^{\mathrm{Aa}}$ & $2,9^{A b}$ & $23,37^{\mathrm{Ac}}$ & $76,62^{\mathrm{Ab}}$ & $35,25^{\mathrm{Ad}}$ \\
\hline CV (\%) & 3,37 & 3,10 & 15,26 & 7,26 & 5,55 & 3,92 \\
\hline
\end{tabular}


L. buchneri. Os menores teores de fração insolúvel potencialmente degradável da PB nas silagens com ureia podem ser explicados, em razão de essas silagens terem apresentado maiores valores de fração solúvel, pois a ureia é $100 \%$ solúvel. E os maiores valores de fração insolúvel potencialmente degradável nas silagens controle podem ser justificados pelo fato dessas silagens apresentarem os menores teores da fração solúvel.

Com relação a taxa de degradação da PB (c), na variedade IAC 86-2480, as silagens com ureia e milho grão moído apresentaram maior valor (3,63 e 3,9\%, respectivamente) $(\mathrm{p}<0,05)$, com as silagens com $\mathrm{NaOH}, \mathrm{CaO}$ e a silagem controle apresentando os menores valores. Na RB 86-7515, as silagens com ureia e milho grão moído apresentaram os maiores valores de taxa de degradação (3,5 e 3,7 \%, respectivamente), com as silagens com $\mathrm{CaO}$ e $L$. buchneri exibindo os menores valores (2,36 e 2,00\%, respectivamente). A diferença entre variedades foi detectada nas silagens com $\mathrm{NaOH}$ e L. buchneri, onde a IAC 86-2480 apresentou valores superiores de taxa de degradação (2,93\%), nas silagens com L. buchneri em relação à RB 86-7515 (2,00 \%). Por outro lado, nas silagens com $\mathrm{NaOH}$ a RB 86-7515 apresentou maior valor de c (2,93 \%) em relação a IAC 86-2480(2,00\%).

Quanto à fração indegradável da PB, na variedade IAC 86-2480, o menor valor de foi encontrado na silagem com ureia $(6,12 \%)$, com os outros aditivos não diferindo entre si. Na variedade RB 86-7515, a silagem com ureia também apresentou menor valor de fração indegradável (9,89\%), seguida pela silagem com $\mathrm{NaOH}(20,58 \%)$, e o maior va-

Tabela V. Desaparecimento da proteína bruta (\%), das silagens de duas variedades de canade-açúcar com diferentes aditivos. (Disappearance of the crude protein (\%) of two varieties of sugarcane ensiled with different additives).

\begin{tabular}{|c|c|c|c|c|c|c|c|c|}
\hline \multirow{2}{*}{$\begin{array}{l}\text { Variedad } \\
\text { Aditivos }\end{array}$} & \multicolumn{7}{|c|}{ Tempos de incubação (horas) } & \multirow[b]{2}{*}{$\mathrm{R}^{2^{\star}}$} \\
\hline & 0 & 6 & 12 & 24 & 48 & 72 & 96 & \\
\hline \multicolumn{9}{|l|}{ IAC 86-2480 } \\
\hline Ureia $^{1}$ & 83,09 & 85,04 & 86,64 & 89,02 & 91,68 & 92,88 & 93,43 & 0,97 \\
\hline $\mathrm{NaOH}^{2}$ & 18,64 & 26,52 & 33,51 & 45,21 & 61,64 & 71,81 & 77,11 & 0,96 \\
\hline $\mathrm{CaO}^{3}$ & 20,37 & 27,32 & 33,38 & 43,31 & 56,69 & 64,49 & 69,05 & 0,97 \\
\hline Milho $^{4}$ & 21,92 & 33,17 & 42,09 & 54,72 & 67,58 & 72,63 & 74,61 & 0,99 \\
\hline L. buchneri ${ }^{5}$ & 20,85 & 29,80 & 37,32 & 48,94 & 62,93 & 69,89 & 73,36 & 0,98 \\
\hline Controle $^{6}$ & 11,31 & 19,52 & 26,76 & 38,78 & 55,36 & 65,37 & 71,41 & 0,95 \\
\hline \multicolumn{9}{|l|}{ RB 86-7515 } \\
\hline Ureia $^{7}$ & 82,09 & 85,99 & 87,66 & 90,08 & 92,65 & 93,88 & 95,27 & 0,95 \\
\hline $\mathrm{NaOH}^{8}$ & 36,69 & 46,65 & 54,29 & 64,64 & 74,31 & 77,65 & 78,80 & 0,96 \\
\hline $\mathrm{CaO}^{9}$ & 11,38 & 28,34 & 40,19 & 54,25 & 64,45 & 66,88 & 67,46 & 0,95 \\
\hline Milho $^{10}$ & 20,54 & 31,72 & 40,14 & 51,27 & 61,17 & 64,35 & 65,38 & 0,97 \\
\hline L. buchneri11 & 11,94 & 16,84 & 21,31 & 28,88 & 40,27 & 48,04 & 52,90 & 0,94 \\
\hline Controle $^{12}$ & 9,91 & 19,05 & 26,85 & 39,19 & 54,71 & 62,94 & 67,30 & 0,98 \\
\hline
\end{tabular}

${ }^{*} R^{2}=$ coeficiente de determinação; ${ }^{1} Y=83,09+10,77\left(1-\mathrm{e}^{-0,033^{*}}\right) ;{ }^{2} \mathrm{Y}=18,65+59,67\left(1-\mathrm{e}^{-0,02^{*} \mathrm{t}}\right) ;{ }^{3} \mathrm{Y}=20,38$ $+55,05\left(1-\mathrm{e}^{-0,023^{*}}\right) ;{ }^{4} \mathrm{Y}=21,92+53,96\left(1-\mathrm{e}^{-0,039^{*}}\right) ;{ }^{5} \mathrm{Y}=20,85+55,94\left(1-\mathrm{e}^{-0,029^{*}}\right) ;{ }^{6} \mathrm{Y}=11,31+69,31$ $\left(1-\mathrm{e}^{-0,021^{*}}\right) ;{ }^{7} \mathrm{Y}=77,31+12,80\left(1-\mathrm{e}^{-0,039^{*}}\right) ;{ }^{8} \mathrm{Y}=36,69+42,72\left(1-\mathrm{e}^{-0,045^{*} \mathrm{t}}\right) ;{ }^{9} \mathrm{Y}=11,38+56,27(1-\mathrm{e}$ $\left.{ }^{0,059 *}\right) ;{ }^{10} \mathrm{Y}=20,54+45,33\left(1-\mathrm{e}^{-0,047^{*}}\right) ;{ }^{11} \mathrm{Y}=8,09+52,95\left(1-\mathrm{e}^{-0,02^{\star} t}\right) ;{ }^{12} \mathrm{Y}=10,92+69,7\left(1-\mathrm{e}^{-0,029^{\star}}\right)$.

Archivos de zootecnia vol. 63, núm. 241, p. 178. 
lor de fração indegradável foi verificado na silagem com milho grão moído (34,12 \%). A diferença entre variedades foi constatada nas silagens com ureia, milho grão moído e L. buchneri. Em todos os tratamentos a variedade IAC 86-2480 revelou os menores valores de fração indegradável. Os menores valores da fração indegradável da PB, nas silagens com ureia, podem ser explicados porque estas silagens apresentaram maior valor de fração solúvel. Na RB 86-7515, a silagem com $\mathrm{NaOH}$ também apresentou baixo valor de fração indegradável (20,58 \%), por ter apresentado alto valor da fração A $(36,69 \%)$, provavelmente por ter solubilizado parte da PB desta silagem.

Na IAC 86-2480, a maior degradabilidade potencial da PB foi encontrada na silagem com ureia $(93,87 \%)$, com os outros tratamentos não diferindo entre si. Essa maior degradabilidade potencial da PB na silagem com ureia, possivelmente, é devido ao maior valor de fração solúvel e à menor fração indegradável, já os outros aditivos não diferiram entre si, provavelmente por não terem apresentado diferença na fração indegradável. Na RB 86-7515, a silagem com ureia exibiu maior degradabilidade potencial (90,10\%), com os menores valores sendo verificados nas silagens com milho grão moído e L. buchneri potencial da PB, provavelmente por terem apresentado os maiores valores de fração indegradável. A diferença entre variedades foi constatada nas silagens com milho grão moído e $L$. buchneri. As silagens da variedade IAC 862480 com esses aditivos revelaram maiores valores de degradabilidade potencial, uma vez que apresentaram menores valores de FI em relação à RB 86-7515.

Na variedade IAC 86-2480, o maior valor de degradabilidade efetiva (DE) da PB foi observado na silagem com ureia (86,02\%), seguida pela silagem com milho (45,55\%), enquanto a controle exibiu o menor valor $(32,42 \%)(p>0,05) . N a$ RB 86-7515, a silagem com ureia apresentou maior valor de degradabilidade efetiva (82,55 \%) seguida pela silagem com $\mathrm{NaOH}(52,41 \%)$, e o menores valores foram verificados nas silagens com CaO, L. buchneri e a silagem-controle. A diferença entre variedades foi constatada nas silagens com ureia, $\mathrm{NaOH}$, milho grão moído e L. buchneri. A variedade IAC 862480 apresentou os maiores valores nas silagens com ureia, milho grão moído e $L$. buchneri. As silagens com ureia apresentaram maior degradabilidade efetiva, provavelmente por possuírem maior fração A, e as silagens controle revelaram menor degradabilidade efetiva, por apresentarem menores valores de fração solúvel da PB.

$\mathrm{Na}$ avaliação da porcentagem de desaparecimento da $\mathrm{PB}$ das silagens, houve superioridade nas silagens com ureia, em todos os tempos (tabela V). No tempo zero, esta superioridade da ureia foi devido ao elevado teor da fração solúvel. Por outro lado, as silagens controle, apresentaram os menores valores.

As silagens com ureia nas variedades IAC 86-2480 e RB 86-7515 apresentaram no último tempo de incubação (96 h) desaparecimento ruminal de 93,43 e 95,27\%, respectivamente. As silagens com $\mathrm{NaOH}$ também demonstraram valores altos, pelo fato deste álcali ter solubilizado parte da proteína dessas silagens. No último tempo de incubação, a silagem da variedade RB 867515 com L. buchneri apresentou o menor desaparecimento ruminal (52,90\%).

As frações potencialmente degradável, fração indegradável e degradabilidade potencial da FDN (tabela VI) não diferiram, em função das variedades e dos aditivos utilizados ( $p>0,05)$. As médias da fração $B$ da FDN nas variedades IAC 86-2480 e RB 867515 de 50,30 e 52,84\%, respectivamente, são superiores aos 38,17 \% encontrados por Pinto et al. (2007), e Fernandes et al. (2003), que registraram 41,11 e 41,29\% para cana de ciclo precoce e intermediário, respectivamente.

Com relação a taxa de degradação (c) da 
FDN, na variedade IAC 86-2480, o maior valor foi encontrado na silagem com milho grão moído, seguida pelas silagens com $\mathrm{NaOH}$ e $\mathrm{CaO}$ e com os outros tratamentos apresentando os menores valores e não diferindo entre si. Já na RB 86-7515, a silagem com $\mathrm{CaO}$ apresentou o maior valor de taxa de degradação da FDN. A diferença entre variedades foi constatada nas silagens com ureia, $\mathrm{CaO}$ e milho grão moído e a variedade IAC 86-2480 apresentou maior valor apenas na silagem com milho grão moído.

A média de taxa de degradação de 2,83 \%h na FDN das silagens com $\mathrm{NaOH}$ desta pesquisa é inferior ao valor de 3,16 \%/h relatado por Pinto et al. (2007) em cana-deaçúcar com $2 \%$ de $\mathrm{NaOH}$, possivelmente, em função do menor teor de $\mathrm{NaOH}(1,5 \%)$ utilizado nessa pesquisa.

Na variedade IAC 86-2480, os menores valores de degradabilidade efetiva da FDN foram encontrados nas silagens com ureia, L. buchneri e a controle. Na RB 86-7515, a silagem com milho grão moído e a controle evidenciaram valores de degradabilidade efetiva inferiores aos outros tratamentos, sendo estes semelhantes entre si. A diferença entre variedades foi constatada nas silagens com ureia, milho grão moído e L. buchneri. A IAC 86-2480 apresentou maior valor de degradabilidade efetiva somente na silagem com milho grão moído.

Os maiores valores da degradabilidade efetiva da FDN, nas silagens com NAOH e $\mathrm{CaO}$, podem ser justificados pelo fato dos álcalis serem capazes de solubilizar

Tabela VI. Parâmetros da degradação ruminal da fibra em detergente neutro das silagens de duas variedades de cana-de-açúcar com diferentes aditivos. (Parameters of the rumen degradation of the neutral detergent fiber of two sugarcane varieties ensiled with different additives).

\begin{tabular}{|c|c|c|c|c|c|}
\hline \multicolumn{6}{|l|}{ Variedades } \\
\hline Aditivos & B & C & $\mathrm{FI}$ & DP & $\mathrm{DE}$ \\
\hline \multicolumn{6}{|l|}{ IAC86-2480 } \\
\hline Ureia & $55,56^{\mathrm{Aa}}$ & $1,50 B^{c}$ & $44,44^{\mathrm{Aa}}$ & $55,56^{\mathrm{Aa}}$ & $12,59^{\mathrm{Bb}}$ \\
\hline $\mathrm{NaOH}$ & $52,63^{\mathrm{Aa}}$ & $2,96^{\mathrm{Ab}}$ & $47,37^{\mathrm{Aa}}$ & $52,63^{\mathrm{Aa}}$ & $19,50^{\mathrm{Aa}}$ \\
\hline $\mathrm{CaO}$ & $49,25^{\mathrm{Aa}}$ & $3,4^{\mathrm{Bb}}$ & $50,75^{\mathrm{Aa}}$ & $49,25^{\mathrm{Aa}}$ & $18,98^{\mathrm{Aa}}$ \\
\hline Milho & $46,35^{\mathrm{Aa}}$ & $4,66^{\mathrm{Aa}}$ & $53,65^{\mathrm{Aa}}$ & $46,35^{\mathrm{Aa}}$ & $22,41^{\mathrm{Aa}}$ \\
\hline L. buchneri & $46,88^{\mathrm{Aa}}$ & $1,80^{\mathrm{Ac}}$ & $53,11^{\mathrm{Aa}}$ & $46,88^{\mathrm{Aa}}$ & $12,38^{\mathrm{Bb}}$ \\
\hline Controle & $49,32^{\mathrm{Aa}}$ & $1,95^{\mathrm{Ac}}$ & $50,68^{\mathrm{Aa}}$ & $49,32^{\mathrm{Aa}}$ & $13,86^{\mathrm{Ab}}$ \\
\hline \multicolumn{6}{|l|}{ RB 86-7515 } \\
\hline Ureia & $52,63^{\mathrm{Aa}}$ & $3,00^{\mathrm{Ab}}$ & $47,37^{\mathrm{Aa}}$ & $52,63^{\mathrm{Aa}}$ & $19,29^{\mathrm{Aa}}$ \\
\hline $\mathrm{NaOH}$ & $45,93^{\mathrm{Aa}}$ & $2,70^{A b}$ & $54,07^{\mathrm{Aa}}$ & $45,93^{\mathrm{Aa}}$ & $16,05^{\mathrm{Aa}}$ \\
\hline $\mathrm{CaO}$ & $40,89^{A a}$ & $5,27^{\mathrm{Aa}}$ & $59,10^{\mathrm{Aa}}$ & $40,89^{\mathrm{Aa}}$ & $20,78^{\mathrm{Aa}}$ \\
\hline Milho & $65,47^{\mathrm{Aa}}$ & $1,40^{\mathrm{Bb}}$ & $34,53^{\mathrm{Aa}}$ & $65,47^{\mathrm{Aa}}$ & $11,91^{\mathrm{Bb}}$ \\
\hline L. buchneri & $67,64^{\mathrm{Aa}}$ & $1,70^{\mathrm{Ab}}$ & $32,36^{\mathrm{Aa}}$ & $67,64^{\mathrm{Aa}}$ & $17,32^{\mathrm{Aa}}$ \\
\hline Controle & $49,39^{A a}$ & $2,17^{A b}$ & $50,61^{\mathrm{Aa}}$ & $49,39^{A a}$ & $12,33^{A b}$ \\
\hline CV (\%) & 23,33 & 26,72 & 24,92 & 23,33 & 13,00 \\
\hline
\end{tabular}

Archivos de zootecnia vol. 63, núm. 241, p. 180. 
Tabela VII. Desaparecimento da fibra em detergente neutro (\%) das silagens de duas variedades de cana-de-açúcar com diferentes aditivos. (Disappearance of the neutral detergent fiber (\%) of two varieties of sugarcane ensiled with different additives).

\begin{tabular}{|c|c|c|c|c|c|c|c|c|}
\hline \multirow{2}{*}{$\begin{array}{l}\text { Variedad } \\
\text { Aditivos }\end{array}$} & \multicolumn{7}{|c|}{ Tempos de incubação (horas) } & \multirow[b]{2}{*}{$\mathrm{R}^{2}$} \\
\hline & 0 & 6 & 12 & 24 & 48 & 72 & 96 & \\
\hline \multicolumn{9}{|l|}{ IAC 86-2480 } \\
\hline Ureia $^{1}$ & 0 & 4,80 & 9,18 & 16,85 & 28,60 & 36,78 & 42,47 & 0,97 \\
\hline $\mathrm{NaOH}^{2}$ & 0 & 8,66 & 15,89 & 26,99 & 40,02 & 46,45 & 49,61 & 0,96 \\
\hline $\mathrm{CaO}^{3}$ & 0 & 9,05 & 16,44 & 27,39 & 39,55 & 44,94 & 47,34 & 0,97 \\
\hline Milho ${ }^{4}$ & 0 & 11,34 & 19,91 & 31,26 & 41,44 & 44,75 & 45,83 & 0,99 \\
\hline L. buchneri ${ }^{5}$ & 0 & 4,81 & 9,13 & 16,48 & 27,17 & 34,1 & 38,59 & 0,98 \\
\hline Controle $^{6}$ & 0 & 5,51 & 10,41 & 18,62 & 30,21 & 37,42 & 41,91 & 0,95 \\
\hline \multicolumn{9}{|c|}{ RB 86-7515Tempos de incubação (horas) } \\
\hline Aditivos & 0 & 6 & 12 & 24 & 48 & 72 & 96 & $\mathrm{R}^{2^{*}}$ \\
\hline Ureia $^{7}$ & 0 & 8,66 & 15,89 & 26,99 & 40,14 & 46,55 & 49,67 & 0,95 \\
\hline $\mathrm{NaOH}^{8}$ & 0 & 6,83 & 12,65 & 21,82 & 33,27 & 39,28 & 42,44 & 0,96 \\
\hline $\mathrm{CaO}^{9}$ & 0 & 11,09 & 19,17 & 29,36 & 37,64 & 39,97 & 40,63 & 0,95 \\
\hline Milho ${ }^{10}$ & 0 & 5,41 & 10,37 & 19,09 & 32,62 & 42,21 & 46,99 & 0,97 \\
\hline L. buchneri11 & 0 & 6,52 & 12,42 & 22,55 & 37,58 & 47,61 & 51,28 & 0,94 \\
\hline Controle $^{12}$ & 0 & 6,00 & 11,27 & 19,98 & 31,87 & 38,96 & 43,18 & 0,98 \\
\hline
\end{tabular}

$\mathrm{R}^{2}=$ coeficiente de determinação; ${ }^{1} \mathrm{Y}=0+55,56\left(1-\mathrm{e}^{-0,015^{*}}\right) ;{ }^{2} \mathrm{Y}=0+52,63\left(1-\mathrm{e}^{-0,0296^{*}}\right) ;{ }^{3} \mathrm{Y}=0+49,25$ $\left(1-\mathrm{e}^{-0,034^{*}}\right) ;{ }^{4} \mathrm{Y}=0+46,35\left(1-\mathrm{e}^{-0,0466^{*}}\right) ;{ }^{5} \mathrm{Y}=0+46,88\left(1-\mathrm{e}^{-0,018^{*} \mathrm{t}}\right) ;{ }^{6} \mathrm{Y}=0+49,32\left(1-\mathrm{e}^{-0,0195^{*}}\right) ;{ }^{7} \mathrm{Y}=0+$ $52,63\left(1-\mathrm{e}^{-0,03^{*}}\right) ;{ }^{8} \mathrm{Y}=0+45,93\left(1-\mathrm{e}^{-0,027^{*}}\right) ;{ }^{9} \mathrm{Y}=0+40,89\left(1-\mathrm{e}^{-0,0527^{*}}\right) ;{ }^{10} \mathrm{Y}=0+65,47\left(1-\mathrm{e}^{-0,014^{*}}\right) ;{ }^{11} \mathrm{Y}=$ $0+67,64\left(1-\mathrm{e}^{-0,017^{*}}\right) ;{ }^{12} \mathrm{Y}=0+49,39\left(1-\mathrm{e}^{-0,0217^{*}}\right)$.

parte da parede celular. Assim, há a expansão da celulose, devido ao rompimento das ligações intermoleculares e solubilização de parte da hemicelulose, facilitando a degradabilidade da fibra pelos microrganismos ruminais. Pedroso et al. (2007) relataram que as silagens tratadas com $\mathrm{NaOH}$ apresentam em média $46 \%$ a mais de digestibilidade que silagens sem aditivos, e que, em relação a cana-de-açúcar fresca, a superioridade varia de 2,2 a 25,6\%. Balieiro Neto et al. (2007), ao avaliarem o $\mathrm{CaO}$ como aditivo na ensilagem de cana, afirmaram que o $\mathrm{CaO}$ pode reduzir os constituintes da parede celular por hidrólise alcalina.

Na avaliação do desaparecimento ruminal da FDN (tabela VII), a silagem com $\mathrm{NaOH}$ na variedade IAC 86-2480 se destacou (49,61\%). Na RB 86-7515, as silagens que se destacaram foram aquelas com ureia $(49,67$ $\%)$ e L. buchneri (51,29 \%). Todavia, a silagem com $L$. buchneri, na IAC 86-2480 apresentou o menor valor, no último tempo de incubação (38,59 \%).

\section{CONCLUSÕES}

$\mathrm{O} \mathrm{NaOH}$ e o $\mathrm{CaO}$ proporcionam maiores degradabilidades efetiva da matéria seca e FDN das silagens de cana. A degradabilidade efetiva da PB é maior nas silagens com ureia. A variedade IAC 86-2480 apresenta melhor valor nutricional em relação à $\mathrm{RB}$ 86-7515, devido à maior degradabilidade efetiva da MS.

\section{AGRADECIMENTOS}

À FAPEMIG e ao CNPq pelo auxílio financeiro. 


\section{SILVAETAL.}

\section{BIBLIOGRAFIA}

Amaral, R.C.; Pires, A.V.; Susin, I; Nussio, L.G.; Mendes, C.Q. e Gastaldello Júnior, A.L. 2009. Cana-de-açúcar ensilada com ou sem aditivos químicos: fermentação e composição química. Rev Bras Zootecn, 38: 1413-1421.

Balieiro Neto, G.; Siqueira, G.R.; Reis, R.A; Nogueira, J.R.; Roth, M.T.P. e Roth, A.P.T.P. 2007. Óxido de cálcio como aditivo na ensilagem de canade-açúcar. Rev Bras Zootecn, 36: 1231-1239.

Cavali, J.; Pereira, O.G.; Sousa, L.O.; Penteado, D.C.S.; Carvalho, I.P.C.; Santos, E.M. e Cezário, A. 2006. Silagem de cana-de-açúcar tratada com óxido de cálcio: composição bromatológica e perdas. Reunião Anual da Sociedade Brasileira de Zootecnia, 43; Anais... Sociedade Brasileira de Zootecnia. João Pessoa.

Fernandes, A.M.; Queiroz, A.C.; Pereira, J.C.; Lana, R.P.; Barbosa, M.H.P.; Fonseca, D.M.; Detmann, E.; Cabral, L.S.; Pereira, E.S. e Vittori, A. 2003. Composição químico-bromatológica de variedades de cana-de-açúcar (Saccharum spp.) com diferentes ciclos de produção (precoce e intermediário) em três idades de corte. Rev Bras Zootecn, 32: 977-985.

Ferreira, D.F. 2000. Analises estatísticas por meio do Sisvar para Windows versão 4.0. Reunião Anual da Região Brasileira da Sociedade Internacional de Biometria, 45. Anais... UFSCar. São Carlos. pp. 255-258.

Freitas, A.W.P.; Pereira, J.C.; Rocha, F.C.; Detmann, E.; Barbosa, M.H.P.; Ribeiro, M.D. e Costa, M.G. 2006. Avaliação da divergência nutricional de genótipos de cana-de-açúcar (Saccharum spp.). Rev Bras Zootecn, 35: 229-236.

Lucci, C.S. 1997. Nutrição e manejo de bovinos leiteiros. Manole. São Paulo. 169 pp.

Marques, T.A. e Silva, W.H. 2008. Crescimento vegetativo e maturação em três cultivares de cana-de-açúcar. Rev Biol Cienc Terra, 8: 5460.

Neter, J; Wasserman, W. and Kutner, M.H. 1985. Linear statistical models: regression, analysis of variance, and experimental designs. $2^{\mathrm{a}} \mathrm{ed}$. Richard D. Irwin. USA. 112 pp.
Nocek, J.E. 1988. In situ and other methods to estimate ruminal proteín and energy digestibility: a review. J Dairy Sci, 71: 2051-2069.

Orskov, E.R. and Mcdonald, I. 1979. The estimation of protein degradability in the rumen from incubation measurements weighted according to rate of passage. J Agr Sci, 92: 499-503.

Passini, R.; Borgatti, L.M.O. e Ferreira, F.A. 2004. Degradabilidade no rúmen bovino de grãos de milho processados de diferentes formas. Pesqui Agropecu Bras, 39: 271-276.

Pedroso, A.F.; Nussio, L.G.; Loures, D.R.S.; Paziani, S.F.; Igarasi, M.S.; Coelho, R.M.; Horri, J. e Rodrigues, A.A. 2007. Efeito do tratamento com aditivos químicos e inoculantes bacterianos nas perdas e na qualidade de silagens de canade-açúcar. Rev Bras Zootecn, 36: 558-564.

Pinto, A.P.; Mizubuti, I.Y; Ribeiro., E.L.A; Rocha, M.A.; Silva Filho, M.F. e Kuraoka, J.T. 2007. Degradabilidade ruminal da cana-de-açúcar integral tratada com diferentes níveis de hidróxido de sódio. Semina: Ciências Agrárias, 28: 503-512.

Reis, R.A.; Garcia, R. e Silva, D.J. 1990. Efeito da aplicação de amônia anidra sobre a composição química e digestibilidade in vitro de fenos de três gramíneas tropicais. Rev Bras Zootecn, 19: 219-224.

SAS Institute. 2000. SAS/STAT User's guide. Version 8. Cary, NC.

Schmidt, P.; Marli, L.J.; Nussio, L.G.; Pedroso, A.F.; Paziani, S.F. e Wechsler, F.S. 2007. Aditivos químicos e biológicos na ensilagem de cana-deaçúcar. 1. Composição química das silagens, ingestão, digestibilidade e comportamento ingestivo. Rev Bras Zootecn, 36: 1666-1675.

Silva, D.J. e Queiroz, A.C. 2002. Análise de alimentos: métodos químicos e biológicos. $3^{\mathrm{a}} \mathrm{ed}$. UFV. Viçosa. 235 pp.

Sniffen, C.J.; Connor, J.D.; Van Soest, P.J.; Fox, D.G. and Russell, J.B. 1992. A net carbohydrate and protein system for evaluating cattle diets: II. Carbohydrate and protein availability. J Dairy Sci, 70: 3562-3577.

Archivos de zootecnia vol. 63, núm. 241, p. 182. 